\title{
Designing an Assessment Model for Entrepreneurial Growth Using a Hybrid Method
}

\author{
Suci Wulandari ${ }^{1, *}$ \\ ${ }^{1}$ Indonesian Center for Estate Crops Research and Development, Bogor, Indonesia \\ ${ }^{*}$ Corresponding author. Email: suciwulandari@hotmail.com
}

\begin{abstract}
Local economic development driven by innovation plays an important role in regional development and generating income. The critical mass of viable ventures is determined by the aspects of entrepreneurship, financing mechanism, and the market mechanism. The traditional commodity-based on production system approach has not looked fitted and tends to shift to a value chain system that is oriented to increase added value and competitiveness. The most important aspect that determines the success of this shifting is the entrepreneurial growth and the information stakeholder involved. These two aspects need to be analyzed simultaneously in an analytical framework with integrated analysis tools. The objectives of this study are to design a conceptual model of entrepreneurial growth and an assessment model for stakeholder involvement analysis by using a hybrid method. Entrepreneurial growth is indicated by entrepreneurial capability and entrepreneurial ecosystem. Entrepreneurial capability consists of entrepreneurial attitude, entrepreneurial learning capacity, and individual resources. Entrepreneurial ecosystem consists of culture, policies and leadership, appropriate finance, quality human capital, markets for products, as well as institutional supports. The stakeholder involved that analyzed in entrepreneurial growth are local government, private sector, business-focused organizations, nongovernmental organization, research and development agency as well as educational institutions. A hybrid method is an analytical approach that used two techniques analysis in integrated model analysis: Analytical Hierarchy Process for weighting analysis, and Simple Additive Weighting for ranking analysis. The proposed model provides a basic assessment framework that can be used in formulating strategies for entrepreneurial-based economic development.
\end{abstract}

Keywords: Model, Entrepreneurial, Growth, Stakeholder, Hybrid.

\section{INTRODUCTION}

Local economic development, as a process that encourages stakeholders to work collectively achieving economic growth and employment generation by improving the locality economy, plays the important role in regional development and generating income. Local economic development encourages the achievement of sustainable performance because it is based on local resources driven by local actors.

The objective of local economic development is to mobilize the local economic potential by bringing innovation to all its growth dimensions that are infrastructure, local business, attracting investment from outside, increasing regional competitiveness, and building local institutions. Local economic development has become a global approach that is generally utilized to address poverty and to create jobs [1].
In economic development, the critical mass of viable ventures is determined by the aspect of entrepreneurship, financing mechanism, and market mechanism [2]. The development support exists at the local government level, with a focus on attracting investments, creating jobs and boosting demand [1]. The traditional commodity-based on production system approach has not looked fitted and tends to shift to a value chain system that is oriented to increase added value and competitiveness. It aligns with the concept that local economic development is a process of social transformation, economic development, and dissemination of innovation [3].

The most important aspect that determines the success of this shifting is the entrepreneurial growth and the information stakeholder involved. These two aspects need to be analyzed simultaneously in an analytical framework with integrated analysis tools. The objectives of this study are to design a conceptual model of entrepreneurial 
growth and an assessment model for stakeholder involvement by using a hybrid method.

\section{RESEARCH METHOD}

A hybrid method is an analytical approach that used two techniques in integrated model analysis: Analytical Hierarchy Process for weighting analysis, and Simple Additive Weighting for ranking analysis. It enables users to integrate stakeholder involvement in entrepreneurial growth measures when evaluating the components of entrepreneurial growth. This helps decision-makers to avoid the mistake of assuming that all aspects of entrepreneurial growth are in the same position due to its important values.

\section{Model Development Stages}

The stages in developing the model consist of:

1. Identify the problem. Analyze problems with an existing system, afterwards produce requirements for a proposed system.

2. Develop a conceptual model. Build a comprehensive and precise structure and behavior of the system in a predefined format [4]. It provides a foundation for the development of the simulation program, as well as for the performance of an intelligent task, such as planning, diagnosis, and design [5].

3. Formulate and develop a model. Develop schematics and network diagrams of the system.

4. Validate the model. Comparing the performance of the developed model with the real situation of a system.

The end-users of the model are the public (government), business (private sector), and nongovernment or non-profit (civil society) sectors in the community.

\section{Analysis Method}

The analysis stages are determining the entrepreneurial growth factors' weight by using the Analytical Hierarchy Process (AHP) and calculating the value of stakeholder involvement by using the Simple Additive Weighting (SAW) method. AHP is a technique which is based on the need of the complex problems branching into a hierarchical structure of specific elements. A hierarchy is identified to show the structure of factors that want to analyze. Then, pairwise comparison and pairwise comparison matrixes for the criteria in each level are obtained according to Saaty's scale. According to the formula, the consistency index is computed. Afterwards, by taking random index values, the consistency ratio using the formula is computed for each matrix to measure whether the relative estimation is viable. The values should be less than or equal to 0.10 for each matrix.
The AHP starts creating a pairwise comparison matrix A. The matrix $A$ is a $m \times m$ real matrix, where $m$ is the number of evaluation criteria considered. Each entry $a_{j k}$ of matrix A represents the importance of the $\mathrm{j}_{\text {th }}$ criterion relative to the $\mathrm{kth}$ criterion. If $\mathrm{a}_{\mathrm{jk}}>1$, then the $\mathrm{j}_{\mathrm{th}}$ criterion is more important than the kth criterion, while if $a_{j k}<1$, then the $j_{\text {th }}$ criterion is less important than the kth criterion. If two criteria have the same importance, then the entry $a_{j k}$ is 1 .

After the matrix A is constructed, it is probable to develop from $\mathrm{A}$ the normalized pairwise comparison matrix $A_{\text {norm }}$ by making equal to 1 the sum of the entries on each column, i.e. each entry $a_{j k}$ of the matrix $A_{\text {norm }}$ is calculated by:

$a j k=\frac{a j k}{\sum_{i=1}^{m} a i k}$

Information:

$\mathrm{a}_{\mathrm{jk}}=$ importance value

The criteria weight vector $\mathrm{w}$ (that is an $\mathrm{m}$-dimensional column vector) is built by averaging the entries on each row of $\mathrm{A}_{\text {norm, }}$, below

$w j=\frac{\sum_{l=1}^{m} a j l}{m}$

Information:

$\mathrm{w}_{\mathrm{j}}=$ weight

Once the weight vector $\mathrm{w}$ and the score matrix $\mathrm{S}$ have been computed, the AHP obtains a vector $\mathrm{v}$ of global scores by multiplying $\mathrm{S}$ and $\mathrm{w}$, i.e.

$v=S * w$

Information:

$\mathrm{v}=$ value

$\mathrm{S}=$ Score matrix

$\mathrm{w}=$ weight

The $i_{\text {th }}$ entry vi of $v$ represents the global score assigned by the AHP to the $i_{\text {th }}$ option. In the last step, a ranking of factors is compared based on the global score calculated. The value of stakeholder involvement is calculated by multiplying the given scale value by the weight of relative importance, to obtain a relative value. Simple Additive Weighting (SAW) is based on the weighted average.

The SAW method requires the process of normalizing the decision matrix $(\mathrm{X})$ to a scale comparable to all existing alternative ratings. The formula for normalization is as follows:

$R i j=\left\{\frac{\frac{\mathrm{xij}}{\mathrm{Max} \times \mathrm{ij}}}{\frac{\mathrm{xij}}{\mathrm{Min} \mathrm{xij}}}\right.$

Information:

$\mathrm{R}_{\mathrm{ij}}$ : Normalized performance rating.

$\operatorname{Max}_{\mathrm{ij}}$ : The maximum value of each row and column. 
$\operatorname{Min}_{\mathrm{ij}}$ : The minimum value of each row and column.

$\mathrm{X}_{\mathrm{ij}}$ : Rows and columns of the matrix.

The preference value for each alternative $(\mathrm{Vi})$ is given as:

$V i=\sum_{j=1}^{n} W j r i j$

Information:

$\mathrm{V}_{\mathrm{i}}$ : The final value of the aspect.

$\mathrm{W}_{\mathrm{j}}$ : The specified weight.

$\mathrm{R}_{\mathrm{ij}}$ : Normalization of the matrix A.

\section{Model Verification and Validation}

Model suitability is analyzed through model verification and validation. Verification is the process of checking whether the model's operational logic matches the flowchart logic. Validation is the process of determining whether a model, as a conceptualization or an abstraction, is a meaningful and accurate representation of a real system. Validation aims to analyze the suitability of the model related to the given task and the sufficiently accurate modelling of the system under consideration [6].

The validation scheme is divided into the importance of model objective, validating model structure, validating model behavior, and validating policy implications [7]. Validation techniques are generally used for validating a simulation model include a comparison to other models, degenerate test, events validity, face validity, historical data validation, predictive validation, scoring model approach, clarity, black-box validation, or extreme condition test [7]. Validation uses a case study as a clarity stage. The case based on integrated cattle livestock system implementation in a palm plantation development area.

\section{RESULT AND DISCUSSION}

The ability to attract investment is determined by the potential for the local economic development of an area which is built based on local conditions and comparative advantages [8]. Local economic development strategies will be prepared based on local economic, social and physical attributes. To build a strong local economy, good practice proves that each community should undertake a collaborative process to understand the nature and structure of the local economy and conduct an analysis of internal and external factors. This will provide information about the main issues and opportunities facing the local economy. An integrated economic development and entrepreneurship plan would appear to be required [9].

Local Economic Development is best achieved through a partnership of governmental authorities and agencies, private sector businesses, non-profit organizations, and citizen engagement, which each partner has an important role to play. Each group of stakeholders uses the result from the model to optimize their unique skills and resources to the process and role to play in representing the best interests.

\section{Conceptual Model}

Entrepreneurial activity varies with the combination of resources, factors or elements that exist in the regions. The identification of the elements, that are crucial to entrepreneurial activity, leads us to have a comprehensive description and analyze it appropriately. Entrepreneurship, as a creative human process which optimizes resources to increase the level of productivity, become a driver of local economic development. It relates to the individual's will of taking on responsibilities and the mental ability to execute the task from the idea and plan into implementation [2].

Entrepreneurship is important in driving economic growth [10]. The process of economic growth is largely determined by innovation, and the entrepreneur is the vehicle to promote new technologies [11]. The production factors capital, labor, technology, and entrepreneurship are the proximate causes of economic development, while institutions are a fundamental cause of economic development [12].

The term of entrepreneurial growth means organization plans to achieve its goals of growing and developing through quality, quantity and turnover. Entrepreneurial growth is a strategic way to build and sustain urban and rural regional economies, while enhance and support entrepreneurship are essential because they cultivate innovation that creates new jobs, new wealth, and a better quality of life [8].

There are some factors affecting venture growth range from macro-socioeconomic factors to entrepreneurs' characteristics [13]. Entrepreneurial growth is affected by entrepreneurial capability in the micro-level and entrepreneurial ecosystem at the macro level. An entrepreneurial capability as a distinct set of individual capabilities and skills aim to explore, integrate, and exploit untapped business opportunities within a market context. An entrepreneurial ecosystem as the social and economic environment affects entrepreneurship [14]. Environmental turbulence can have a significant impact on the performance of an organization [15], hence entrepreneurs should have information about whether growth through internal resources is sufficient and in line with the goals and objectives [16].

There are some internal and external factors that impact entrepreneurial growth. From the resource-based view, many have studied the importance of internal and external organizational resources [17]. Internal factors are factors that are owned by individuals, while external factors are factors that encourage entrepreneurial growth in the form of various supports in physical and nonphysical forms. 
Another term used in predicting entrepreneurial growth is micro variables and macro variables. Micro variables are further categorized into intrinsic pull and extrinsic push factors, while macro variables are tested as moderators in the motivation-growth relationship [18]. The micro behavioral perspective is primarily concerned with the characteristics of individual entrepreneurs, including experience, education, innovativeness, locus of control, risk-taking behavior, sacrifice, and motivation [18] [15].

Internal factors that influence entrepreneurial growth are education and training, entrepreneurial factors, storage and infrastructure, while external factors are market factors [18]. Motivation, aspiration, intention, mindset, priorities, skills, education, background, experience, social networking, and entrepreneurial capital are the internal factors have a profound effect on the growth of the firm [19]. Entrepreneurship is induced by an individual's attitudes or motives, skills and psychological endowments [20]. Entrepreneurial attitudes like perceptions, intentions, and role models, have positive effects on economic growth [10].

Corporate culture, strategies, policies, and decisions are made in line with growth aspirations. A stable macroeconomic environment, local physical infrastructure, tax level, quality of institutions, primary education and health, are factors which influence any economic activity, and policy issues that directly affect entrepreneurship [20].

The promotion of entrepreneurship at the national and local level rests on two primary pillars: strengthening of entrepreneurial skills, and improvement of the entrepreneurial framework conditions [20]. Entrepreneurship ecosystem for economic development is related to a conducive culture, enabling policies and leadership, availability of appropriate finance, quality human capital, venture friendly markets for products, and a range of institutional supports [21] [22] [22]. Each context requires its ecosystem as the components of the system include several units and pieces that interact in different distinctive ways based on the context of the entrepreneurship activities.

The business environment, as an external factor, has a strong significant relationship with motivation to start a business [23]. On the other hand, stimulating entrepreneurship only will be insufficient, since attracting entrepreneurs with low human capital levels will not contribute to economic growth [12]. As external constraints are primarily exogenous, more effort should be made to overcome the limitations of internal entrepreneurship for micro-enterprises to experience growth.

Entrepreneurial growth is influenced by entrepreneurial capability and entrepreneurial ecosystem (Figure 2). In this study, these factors are described by referring to several works of literature. Entrepreneurial capability consists of entrepreneurial attitude, entrepreneurial learning capacity, and individual resources. Entrepreneurial attitude generally includes aspiration, mindset, and intention, while entrepreneurial learning capacity is described by knowledge, skills, and experience. Individual resources are about investment capital, technology, and networks. Entrepreneurial ecosystem consists of culture, policies and leadership, appropriate finance, quality human capital, venture friendly markets for products, and institutional supports. Culture consists of societal norm and success story, while policies and leadership are reflected by government and leadership. Finance includes credit access and credit availability, while human capital consists of labor and educational institution. Venture friendly markets for products include market network and early customer, while institutional support consists of infrastructure and support profession.

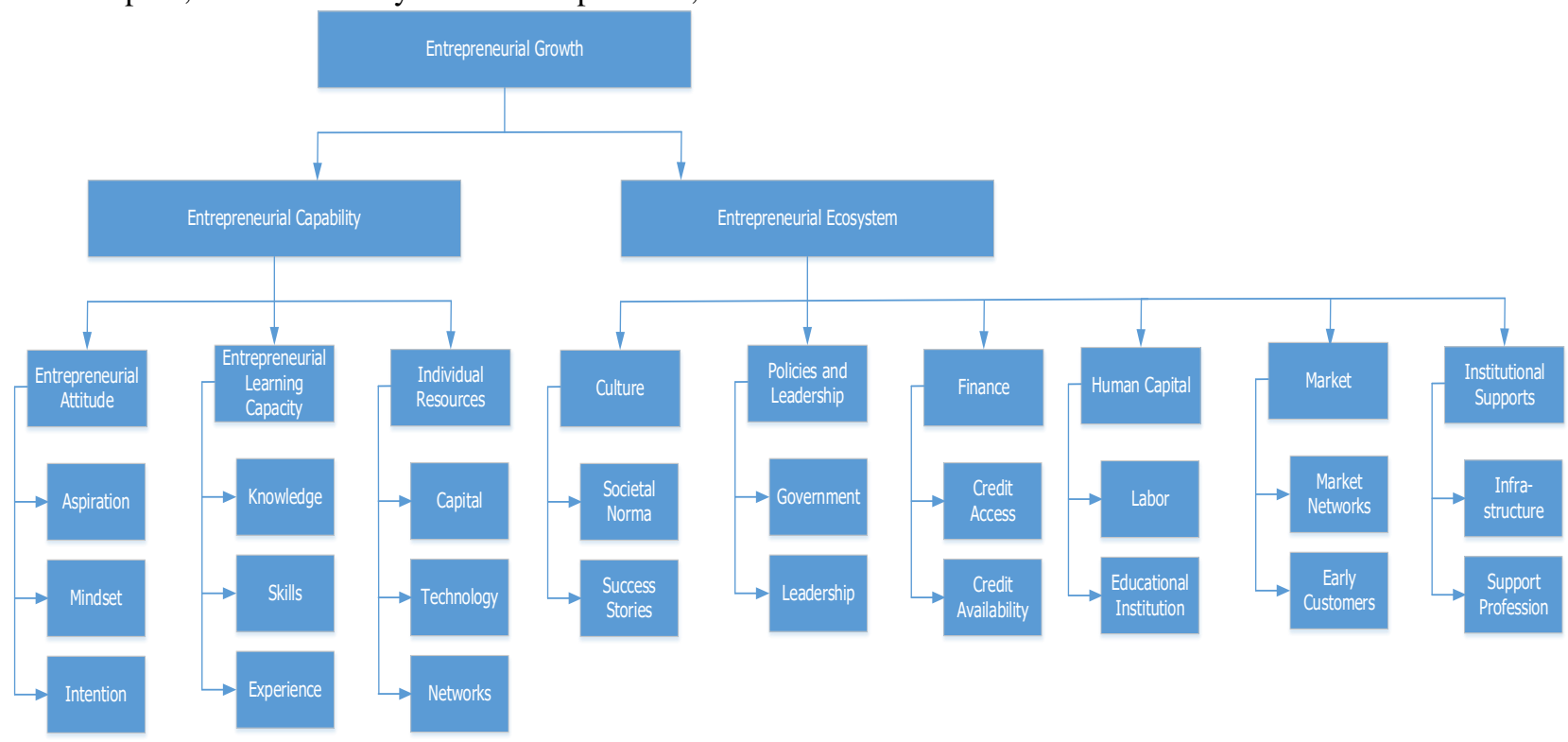

Figure 1. Conceptual model of entrepreneurial growth analysis 


\section{Stakeholders in promoting Entrepreneurial Growth}

Institutions involved in Local Economic Development are not only single institutions but are more directed to a group of institutions that work together to support the program. Hence, analyzing the scale of contribution or participation in each factor will describe the level of stakeholder's involvement.

The collection of these institutions can be in the form of government field agents; international NGO, local NGO, and Community Based Organizations field agents; private sector field agents; community volunteers; private sector ICT-based on service providers; and businessfocused organizations [24]. The other institutions involved are research agency and educational institution. Therefore, the stakeholder involved in entrepreneurial growth are local government, private sector, businessfocused organizations, NGO, research and development agency and educational institutions.

\section{Model Development}

\section{Input Design}

The relative importance between the two criteria is measured according to Saaty's 1-9 scale of pairwise comparison, as shown in Table 1. The score used to calculate for SAW is $0-1$ indicate the involvement of stakeholders in each factor.

Table 1. Saaty Scale

\begin{tabular}{|c|l|}
\hline Value of $\mathbf{a}_{\mathbf{j k}}$ & Interpretation \\
\hline 1 & $\mathrm{j}$ and k are equally important \\
\hline 3 & $\mathrm{j}$ is slightly more important than $\mathrm{k}$ \\
\hline 5 & $\mathrm{j}$ is more important than $\mathrm{k}$ \\
\hline 7 & $\mathrm{j}$ is strongly more important than $\mathrm{k}$ \\
\hline 9 & $\mathrm{j}$ is absolutely more important than $\mathrm{k}$ \\
\hline $2,4,6,8$ & in between \\
\hline
\end{tabular}

Process Design

The stages to calculate entrepreneurial growth is enumerated below:

1. Calculating the weight of the factors and elements of entrepreneurial growth using the AHP. Construct a pair-wise comparison matrix (2x2) for criteria entrepreneurial capability and entrepreneurial ecosystem with respect to entrepreneurial growth by using Saaty's 1-9 scale of pairwise comparison. In level 2, develop a pair-wise comparison matrix $(3 \times 3)$ for entrepreneurial capability and matrix $(6 \times 6)$ for entrepreneurial ecosystem. This stage is followed by a pair-wise comparison matrix $(3 \times 3)$ for entrepreneurial attitude, entrepreneurial learning capacity, and individual resources, and matrix (2x2) for culture, policies and leadership, finance, human capital, markets, and institutional supports.

2. Scoring the performance of every stakeholder for each factor.

3. Calculating the value by using SAW

4. Interpreting of stakeholders' involvement in promoting entrepreneurial growth

\section{Output Design}

The resulting output is the weight of factors in entrepreneurial growth and the value of the stakeholder potential involvement in promoting entrepreneurial growth.

Table 2. Range of value of stakeholder potential involvement

\begin{tabular}{|l|l|}
\hline Value & Linguistic \\
\hline $0,001-0,200$ & Very low potential involvement \\
\hline $0,201-0,400$ & Low potential involvement \\
\hline $0,401-0,600$ & Moderate \\
\hline $0,601-0,800$ & High potential involvement \\
\hline $0,801-1,000$ & Very high potential involvement \\
\hline
\end{tabular}

An entrepreneurial capability as a distinct set of individual capabilities and skills aim to explore, integrate, and exploit untapped business opportunities within the market context. An entrepreneurial ecosystem as the social and economic environment affects local or regional entrepreneurship. The value is used as a basis for formulating strategies in developing entrepreneurial aspects to support local economic development.

\section{Case Study}

The integrated cattle livestock system is a form of mixed production that utilizes crops and livestock to reduce the openness of nutrient cycles [25]. The palm cattle integration is an integrated cattle livestock system where the business activities of oil palm plantations and cattle farming are combined in the same area with a close relationship between plant and livestock components that use each other's waste [26]. The performance of the implementation of the integrated cattle livestock system in a palm plantation area development is not optimal due to the willingness to implement and knowledge of the farmers.

The local government want to accelerate its implementation, however, limited resources should be into account taking. Participatory implementation hence is a strategic way to overcome and entrepreneurial growth is an important aspect to leverage the milestone. 
Based on the field observation and in-depth interview, below is a matrix for example to analyze entrepreneurial capability (Figure 2). The result of the analysis by using AHP is about the weight of entrepreneurial growth factors (Figure 3). Knowledge, infrastructure, and supporting professions are the factors that are considered the most important compared to other factors.

\begin{tabular}{|l|l|l|l|}
\hline & $\begin{array}{c}\text { Entrepreneurial } \\
\text { Attitude }\end{array}$ & $\begin{array}{c}\text { Entrepreneurial } \\
\text { Learning } \\
\text { Capacity }\end{array}$ & $\begin{array}{l}\text { Individual } \\
\text { Resources }\end{array}$ \\
\hline $\begin{array}{l}\text { Entrepreneurial } \\
\text { Attitude }\end{array}$ & & 2 & 3 \\
\hline $\begin{array}{l}\text { Entrepreneurial } \\
\text { Learning } \\
\text { Capacity }\end{array}$ & & & 3 \\
\hline $\begin{array}{l}\text { Individual } \\
\text { Resources }\end{array}$ & & & \\
\hline
\end{tabular}

Figure 2. The pair-wise comparison matrix for entrepreneurial capability.

\section{Synthesis with respect to: \\ Goal: Entrepreneurial Growth}

Overall Inconsistency $=.04$

Aspiration
Mindset
Intention
Knowledae
Skills
Exnerience
Capital
Technology
Network
Societal Norm
Success Stories
Government
Leadershin
Credit Access
Credit Availability
Labor
Educational Institution
Market Networks
Early Customers
Infrastructure
Supbort Profession

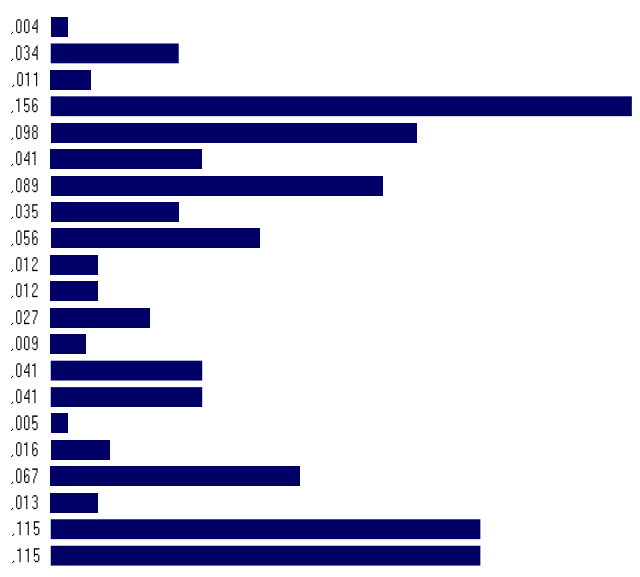

Figure 3. Weight of factors of entrepreneurial growth

Evaluating the potential stakeholder involvement in promoting entrepreneurial growth is conducted by assessing the role of every stakeholder in each entrepreneurial growth factor. The result showed that local business sector $(0,888)$ has the highest value of potential involvement, followed by local government $(0,863)$ and non-governmental organization $(0,814)$ (Table 3).

Table 3. Value of potential stakeholders' involvement

\begin{tabular}{|l|l|}
\hline \multicolumn{1}{|c|}{ Stakeholders } & $\begin{array}{c}\text { Value of Potential } \\
\text { Involvement }\end{array}$ \\
\hline Local government & 0,863 \\
\hline Local business sector & 0,888 \\
\hline
\end{tabular}

\begin{tabular}{|l|c|}
\hline $\begin{array}{l}\text { Business focus } \\
\text { organization }\end{array}$ & 0,656 \\
\hline $\begin{array}{l}\text { Non-Governmental } \\
\text { Organization }\end{array}$ & 0,814 \\
\hline $\begin{array}{l}\text { Research and development } \\
\text { agency }\end{array}$ & 0,535 \\
\hline Educational institution & 0,551 \\
\hline
\end{tabular}

The local business sector and local government have a very high potential involvement. Accelerating palm cattle integration implementation can be led by the local government and the local business sector, and donors. The program focuses on the leverage factors: increase knowledge by developing knowledge management model, followed by providing infrastructure and support profession.

\section{CONCLUSION}

Entrepreneurial growth is influenced by entrepreneurial capability and entrepreneurial ecosystem. Entrepreneurial capability consists of entrepreneurial attitude, entrepreneurial learning capacity, and individual resources. Entrepreneurial attitude generally refers to aspiration, mindset, and intention, while entrepreneurial capability is related to knowledge, skills, and experience. Individual resources are about investment capital, technology, and networks. Entrepreneurial ecosystem consists of culture, policies and leadership, appropriate finance, quality human capital, venture friendly markets for products, and institutional supports. The stakeholder involved that analyzed in entrepreneurial growth are local government, private sector, business-focused organizations, non-governmental organization, research and development agency, as well as educational institutions.

A hybrid method is an analytical approach that used 2 techniques analysis in integrated model analysis Analytical Hierarchy Process and Simple Additive Weighting. The stages of analysis include: calculating the weight of the factors and elements of entrepreneurial growth using the AHP, scoring the performance of each element, calculating the value by using SAW, and interpreting of stakeholders' involvement in promoting entrepreneurial growth.

\section{REFERENCES}

[1] D. F. Meyer, "Local Economic Development (LED), challenges and solutions: The case of the Northern Free State Region, South Africa," Mediterr. J. Soc. Sci., vol. 5, no. 16, pp. 624-634, 2014.

[2] S.-G. Toma, A.-M. Grigore, and P. Marinescu, "Economic development and entrepreneurship," 
Procedia Econ. Financ., vol. 8, no. 14, pp. 436-443, 2014.

[3] R. E. Supriyadi, "Local economic development and triple helix: Lesson learned from role of universities in Higher Education Town of Jatinangor, West Java, Indonesia," Procedia - Soc. Behav. Sci., vol. 52, pp. 299-306, 2012.

[4] S. Robinson, G. Arbez, L. G. Birta, A. Tolk, and G. Wagner, "Conceptual modeling: Definition, purpose and benefits," in Proceedings - Winter Simulation Conference, 2016, no. April 2016, pp. 2812-2826.

[5] N. Guarino, G. Guizzardi, and J. Mylopoulosc, "On the philosophical foundations of conceptual models," Front. Artif. Intell. Appl., vol. 321, pp. 1-15, 2019.

[6] R. G. Sargent, "Verification and validation of simulation models," J. Simul., vol. 7, no. 1, pp. 1224, 2013.

[7] M. S. Martis, "Validation of simulation based models: A theoretical outlook," Electron. J. Bus. Res. Methods, vol. 4, no. 1, pp. 39-46, 2006.

[8] M. Fortunato, D. McLaughlin, and T. Alter, "The individual-institutional-opportunity nexus in entrepreneurship: Bridging perspectives in entrepreneurship and local economic development," in 50th Congress of the European Regional Science Association: "Sustainable Regional Growth and Development in the Creative Knowledge Economy", 19-23 August 2010, Jönköping, Sweden, 2010, pp. 131.

[9] R. R. Stough, "Entrepreneurship and regional economic development: Some reflections," Investig. Reg. - J. Reg. Res., vol. 36, pp. 129-150, 2016.

[10] J. Doran, N. McCarthy, and M. O'Connor, "The role of entrepreneurship in stimulating economic growth in developed and developing countries," Cogent Econ. Financ., vol. 6, no. 1, 2018.

[11] M. Á. Galindo and M. T. Méndez-Picazo, "Innovation, entrepreneurship and economic growth," Manag. Decis., vol. 51, no. 3, pp. 501-514, 2013.

[12] E. Stam and A. van Stel, "Types of entrepreneurship and economic growth," 2009.

[13] B. Jin and D. A. Kirsch, "Entrepreneurial growth as a process: Mechanism-based theorizing," in Advances in Entrepreneurship, Firm Emergence and Growth, vol. 17, 2015, pp. 63-94.

[14] Z. Abd-Hamid, N. A. Azizan, and S. Sorooshian, "Predictors for the success and survival of entrepreneurs in the construction industry," Int. J. Eng. Bus. Manag., vol. 7, no. 1, pp. 1-11, 2015.

[15] D. Valliere and R. Peterson, "Entrepreneurship and economic growth: Evidence from emerging and developed countries," Entrep. Reg. Dev., vol. 21, no. 5-6, pp. 459-480, 2009.

[16] S. F. H. Shah, T. Nazir, K. Zaman, and M. Shabir, "Factors affecting the growth of enterprises: A survey of the literature from the perspective of smalland medium-sized enterprises," J. Enterp. Transform., vol. 3, no. 2, pp. 53-75, 2013.

[17] D. Urbano and A. Turró, "Conditioning factors for corporate entrepreneurship: An in(ex)ternal approach," Int. Entrep. Manag. J., vol. 9, no. 3, pp. 379-396, 2013.

[18] J. Liao, H. P. Welsch, and S. Drive, "Internal and external predictors of entrepreneurial growth: An empirical investigation of the moderating effects of infrastucture elements," Thirtheenth Annu. United States Assoc. Small Bus. Entrep. Conf., no. January 1999, 1999.

[19] D. Mahadea and S. Khumalo, "Understanding the internal and external constraints to growth of microenterprise entrepreneurship in a South African provincial context: A case of MpumalangaMkhondo," J. Dev. Entrep., vol. 25, no. 2, pp. 1-24, 2020.

[20] T. Rahmije, "The role of entrepreneurship and enterprises for local economic development," Acad. Int. Sci. J., vol. 5, no. 1934, pp. 96-107, 2012.

[21] I. Khattab and O. O. Al-Magli, "Towards an integrated model of entrepreneurship ecosystem," $J$. Bus. Econ. Policy, vol. 4, no. 4, pp. 80-92, 2017.

[22] S. R. Sardeshmukh and A. C. Corbett, "The duality of internal and external development of successors: Opportunity recognition in family firms," Fam. Bus. Rev., vol. 24, no. 2, pp. 111-125, 2011.

[23] H. G. Fereidouni, T. A. Masron, and D. Nikbin, "Consequences of external environment on motivation in Iran," Acad. Manag. J., vol. 15, no. 2, pp. 175-196, 2010.

[24] S. Ferris et al., "Linking smallholder farmers to markets and the implications for extension and advisory services," 2014.

[25] D. J. Isenberg, "The entrepreneurship ecosystem strategy as a wew paradigm for economic policy: Principles for cultivating entrepreneurship," 2011.

[26] S. Edwina, Y. Jum'atri, Yusmini, and M. Evi, "Kajian perbandingan produktivitas dan pendapatan perkebunan pola Sistem Integrasi Sapi dan Kelapa Sawit (SISKA) dengan perkebunan tanpa pola SISKA di Kabupaten Siak," J. Pemikir. Masy. Ilm. Berwawasan Agribisnis, vol. 5, no. 1, pp. 90-103, 2019. 